\title{
An Exploration to the Roles of School Nurses in Bahrain's Government and Private Schools
}

Faten Hassani

Department of Nursing and Midwifery, Royal College of Surgeons in Ireland, Dublin, D02 YN77, Kingdom of Bahrain

Abstract

School Nurses having a very critical role nowadays in the school. Their role is very important in ensuring that the students achieve their academic success. The nurse's major role in both the government and private schools is to promote students' healthcare and their well-being. This study's major objective was to find out the roles played by the school nurses of Bahrain and compare the differences between the roles of the nurses in the two different settings. The study used both qualitative and quantitative study design to collect data. This move very strategic since the two methods complemented each other and covered the gaps created by using one of the method. Qualitative data was analyzed using Burnard's thematic analysis tool while SPPS was used to analyze quantitative data.

\section{Introduction}

Nurses are healthcare workers who treat sick and injured people in most healthcare centers. In the Gulf region, nurses are now shifting from the traditional areas of work such as government healthcare centers to offer services in the schools [1]. School nurses are not fully recognized in this region despite playing a very critical in the education system through providing healthcare to students and making sure that they are healthy and safe to learn as per the National Association of School Nurses [NASN], [2]. In Bahrain, many schools do not have nurses and the few schools which have them; the nurse's roles are not well distinguished. The aims of this study were to:

1. Explore school nurse's role in the Gulf and other countries

2. Explore school nurse's role in Bahrain governmental schools

3. Explore the role of nurses in Bahrain private schools and

4. Explore the comparison between the role of school nurses in private schools and government schools.

The current study investigated the roles of school nurses both in the government and private schools to find out if the nurse's roles were clearly distinguished, and find out the differences which existed between the roles of government school nurses and private school nurses in Bahrain. Both qualitative and quantitative methods were study to conduct the research. The use of mixed methods enabled the study to come up with sufficient data that complemented each other [3] in finding out the role of the school nurses.

\section{Methodology}

The study used mixed methods study design-qualitative and quantitative methods in their research process. The qualitative methods chose a sample of $27 \mathrm{school}$ nurses with the use of a purposive sampling process. The qualitative method used a total "population sampling technique." Quantitative data was collected using 3 pretested and pre-validated measurement scales of job satisfaction while qualitative data were collected using semi-structured interviews. The data collected was analyzed using descriptive statistics and SPSS for qualitative data. The 6-stage thematic analysis tool by Burnard [4] was used to analyze the qualitative data collected from interviews.

\section{Findings and Discussion of Findings}

\section{The role of school nurses in the Gulf and the other countries}

In Arabian nations the school nurses are expected to provide quality health care and nursing intervention for the real and the potential health challenges in the students. They give direct care needs of the students through involving medication administration and the routine follow ups and treatment process [5]. The roles of the school nurses in the gulf are to ensure academic success by satisfying all the health needs of students during their time at school. The school nurses provide direct healthcare to the students. Their roles involve caring for injured students and those with acute challenges. The school nurses of the gulf and others from different countries also offer special healthcare needs. This may include students with asthma and also managing their emergency conditions [6]. The school nurses also offer care services to the teachers of the school including the families of the school children. The school nurses also develop patient-centered healthcare for students with demanding conditions. The nurse has to screen and educate the students on the potential emerging events like asthma and diabetic as per Perry and Toole, [7]. In countries like England, the school nurses are responsible for addressing the social determinants of health like housing, income, transportation and environmental health. The school nurses have established that many students do not attend school due to health concerns. Therefore, it is their duty to assess these factors and come up better health plan for every child. In United States, the school nurse employs the primary prevention through offering health education which promotes the mental and physical health. They also come up with informed healthcare decisions which prevent diseases and improve the school performance [8]. In the European schools, the school nurses are expected to address the healthy lifestyles which should minimizing of risk behaviors, daily

"Corresponding Author: Dr. Faten Hassani, Department of Nursing and Midwifery, Royal College of Surgeons in Ireland, Dublin, D02 YN77, Kingdom of Bahrain; E-mail: fatengov@gmail.com

Citation: Hassani F (2021) An Exploration to the Roles of School Nurses in Bahrain's Government and Private Schools. Int J Nurs Clin Pract 8: 337. doi: https://doi.org/10.15344/2394-4978/2021/337

Copyright: (C) 2021 Hassani. This is an open-access article distributed under the terms of the Creative Commons Attribution License, which permits unrestricted use, distribution, and reproduction in any medium, provided the original author and source are credited. 
activities developmental needs and "self-preventive care" [9].

\section{The Role of school nurses in Bahrain in governmental schools}

The results indicated that school nurses had the role of preparing the clinical room which included demarcating the room in different regions like reception, pharmacy, and administrative rooms. P9 stated: "...we have to do the set with where I will keep my patients, where I will do the dressing, where I will keep them for rest, where I will keep my medications, where I will keep my records, and where I will keep my office." This was represented by $78.6 \%$ of the nurses. The nurses also prepared the students and the school staff files. P1 explained: " $I$ prepare the medical file for all students so we will know the diseases and the blood or hereditary diseases that the students suffer from, and for teaching the administrative staff of the school as well as the workers". Another role was to emergency preparation. $\mathrm{P} 20$ stated: "... if I have an emergency case, we are calling 999." $(\mathrm{M}=3.76, \mathrm{SD}=0.94)$. The nurses in Bahrain have to create health awareness to the students and school staff. P1 explained: "We conduct lectures and workshops, and we organize health events... the aim of the health events is spreading health awareness and modifying behavior." The nurses were also responsible for coordinating with the supplies and logistics to foresee the safe delivery of the medical supplies. P14 stated his logistical role as "bringing the needed medicines and surgical materials, preparing first aid bags for all school sections, and also checking the medical equipment, such as blood pressure machines and HGT machines" $(\mathrm{M}=3.87, \mathrm{SD}=$ $0.45)$.

\section{The Role of school nurses in Bahrain in private schools}

The private school nurses have to prepare the nursing room. P18 says that "...I establish my clinic by arranging the furniture inside the clinic. I have changed some; for example, the bed, the office-I put up some decorations to make it more attractive for the kids." They also offer healthcare to the students and the school staff including the parents. $82.2 \%$ of nurses agreed to this role, P22 says that "So we're taking care of all aspects: parents and teachers." They also offer health education to optimize on the healthcare needs of the school; $76.2 \%$ agreed to do this task, P19 says that "health education. Especially during the opening of classes, we have orientations for KG, the primary schoolers, and the intermediates. We're giving lectures about how to take care of their bodies and proper hygiene, especially for the intermediates at puberty age." The nurses also examine, diagnose, treat and give referrals based on the student health conditions. P2 claimed that "[There are many] school workshop accidents, since we have a lot of workshops for carpentry, car repair, iron moulding and electricity... I treat them, and sometimes I transfer them to the local health centre".

The comparison between the role of school nurses in private schools and governmental schools

The government school nurses are hired and paid by $\mathrm{MoH}$ which is not the case for the private schools. The governmental school nurses had the opportunity to participate in joint meetings organized for the nurses to advance their competencies. However, in private school nurses, they do not participate in any programs meeting P19 stated that "Were not part of it (the school health programme). So we're just doing our job at the school health clinic and for the school administration. And then if we have some problems, we'l just contact the Ministry of Health". Another difference between private and public nurses is the differing roles. The private nurses had specific roles to perform while the public nurses did not have clarity on the role they played. P1 claimed that "They should know the role of the nurse in the school. They should have a list of the nurse's duties, and they should not ask her to do extra duties." $65 \%$ of the government school nurses did not have clarity in their roles. It is also important to note that both government school nurses and private school nurses played a significant role in Bahrain offering comprehensive healthcare to the students and the school staff. The scope of treatment in government school nurses is limited by the $\mathrm{MoH}$ when compared to the private school nurses. P18 stated that ... "Because we don't have any orders from the Ministry of Health or from the management, we cannot help the students. Though 140 we have learned it but we are not, we should not practice it in the school. Because of that, we are limited with them." Both the government school nurses and the private school nurses have to inspect all the students and their vaccination records and liaise with the government carry out vaccination to the students in needs of the vaccines. P6 said that "Yes, vaccinations are very important in the duty of school nurses. We have to check our students' vaccinations records". Also P15 said that "Then every year, we conduct the vaccination program... We do it two times a year. If we have a disease outbreak, we do vaccinations, and we have the routine vaccination program".

\section{Conclusion}

It is very important to keep school nurses in Bahrain because they treat the students and staff illnesses and injuries and make sure that they are safe and in good health condition. It also important to the school nurses since they prepare the clinical room, coordinating with the logistics for safe supply of medical supplies and come up with healthcare promotion programs in the school to create awareness for various diseases like the communicable ailments.

\section{Further Research}

More research is needed in the future suggesting the development plan which identifies the roles school nurses planning to in higher learning institutions like universities. This is because the university population greatly differs from that of school.

\section{Competing Interests}

The author declare that there is no competing interests regarding the publication of this article.

\section{References}

1. Shaffer FA (2017) An Unconventional Path Leads to a Lifetime Commitment to the Nursing Profession. Nurs Adm Q 41: 247-251.

2. National Association of School Nurses (2017) The role of the 21st Century school nurse. National Association of School Nurses Position Paper.

3. McCusker K, Gunaydin S (2015) Research using qualitative, quantitative or mixed methods and choice based on the research. Perfusion 30: 537-542.

4. Burnard P (1991) A method of analyzing interview transcripts in qualitative research. Nurse Education Today 11: 461-466.

5. Lineberry MJ, Ikes MJ (2015) The role and impact of nurses in American elementary schools: A systematic review of the research. The Journal of School Nursing 31: 22-23.

6. Adams S (2009) Use of evidence-based practice in school nursing: Survey of school nurses at a national conference. J Sch Nurs 25: 302-313.

7. Perry C, Toole K (2000) Impact of School Nurse Case Management on Asthma Control in School-aged Children. J Sch Health 70: 303-304.

8. Schaffer MA, Anderson L, Rising S (2016) Public health interventions for school nursing practice. J Sch Nurs 32: 195-208

9. Baisch MJ, Lundeen SP, Murphy MK (2011) Evidence-based research on the value of school nurses in an urban school system. J Sch Health 81: 74-80. 